
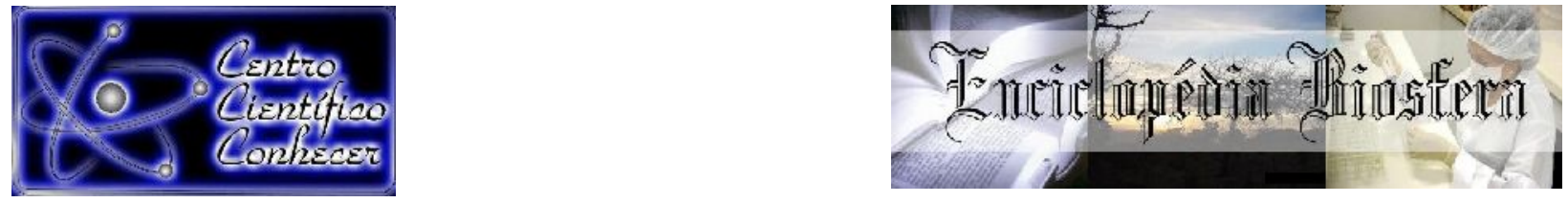

\title{
CARCINOMA DE CÉLULAS ESCAMOSAS PRIMÁRIO DE MAMA COM METÁSTASE EM LINFONODO REGIONAL EM CADELA - RELATO DE CASO
}

Bethânia Almeida Gouveia1, Marco Aurélio da Cunha Dias², Beatriz Furlan Paz ${ }^{3,}$ Alessandra Aparecida Medeiros-Ronchi ${ }^{4}$

1- Discente da Faculdade de Medicina Veterinária da Universidade Federal de Uberlândia, Uberlândia, Brasil. Email: bethania agouveia@hotmail.com

2- Médico Veterinário, Residente do Programa de Residência Multiprofissional em Saúde, área de Patologia Animal, Universidade Federal de Uberlândia, Uberlândia, Uberlândia, Brasil.

3- Médica Veterinária, Residente do Programa de Residência Multiprofissional em Saúde, área de Cirurgia de Pequenos Animais, Universidade Federal de Uberlândia, Uberlândia, Brasil.

4- $\quad$ Professora, Laboratório de Patologia Animal, Faculdade de Medicina Veterinária da Universidade Federal de Uberlândia, Uberlândia, Brasil.

Recebido em: 22/09/2018 - Aprovado em: 23/11/2018 - Publicado em: 03/12/2018 DOI: 10.18677/EnciBio_2018B24

\begin{abstract}
RESUMO
Carcinoma de células escamosas (CCE) cutâneos são neoplasias comuns nas espécies domésticas, porém pouco frequentes na glândula mamária. Objetivou-se relatar um caso de CCE primário de mama com metástase em linfonodo regional e seus achados histopatológicos. O animal em questão era uma cadela, sem raça definida, de dez anos de idade, com histórico de neoplasia na região abdominal, com recidiva após remoção cirúrgica. O animal foi encaminhado para avaliação clínica apresentando em mamas abdominais caudais direita e esquerda e inguinais direita e esquerda, massas ulceradas e aderidas em musculatura. A paciente em questão foi submetida à mastectomia para remoção da neoplasia e posteriormente realização de exame histopatológico. Microscopicamente observou-se proliferação de células epiteliais arranjadas ora em ninhos, cujo centro encontrava-se preenchido por pérolas de queratina. As células apresentaram formato variando de arredondado a poliédrico, com citoplasma amplo, eosinofílico, núcleo central, ovalado, cromatina frouxa e nucléolo evidente, por vezes múltiplo. Notou-se também pleomorfismo celular, com elevada anisocitose e anisocariose. Foi diagnosticado CCE mamário. O linfonodo inguinal esquerdo apresentava perda da arquitetura normal em decorrência da invasão da córtex e medular por células epiteliais neoplásicas, que se organizavam formando ninhos, cujo centro encontrava-se preenchido por pérolas de queratina. Este relato de CCE mamário em cadela demonstra a importância de um acompanhamento oncológico atencioso em quadros de neoplasias mamárias com invasões em vasos linfáticos e recidivas, mesmo após remoção cirúrgica.
\end{abstract}

PALAVRAS-CHAVE: cão, diferenciação escamosa, neoplasia mamária. 


\title{
SQUAMOUS CELL CARCINOMA BREAST PRIMARY WITH METASTASIS FOR LYMPH NODE
}

\begin{abstract}
Cutaneous squamous cell carcinoma (SCC) are neoplasms common in domestic species, but uncommon in the mammary gland. The objective of this study was to report a case of primary breast SCC with regional lymph node metastasis and its histopathological findings. The animal in question was a 10-year-old undefined female dog with a history of neoplasia in the abdominal region, with recurrence after surgical removal. The animal was taken for clinical evaluation presenting on right and left abdominal caudal mammary glands, and right and left inguinal mammary glands, ulcerated masses and adhered to musculature. The patient underwent mastectomy to remove the neoplasm and subsequently performed histopathological examination. Microscopically, there was proliferation of epithelial cells arranged in nests, the center of which was filled with keratin pearls. The cells presented a variety ranging from rounded to polyhedral, with broad cytoplasm, eosinophilic, central nucleus, loose chromatin and evident, sometimes multiple, nucleolus. Cellular pleomorphism was also observed, with high anisocytosis and anisocariosis. It was given the diagnose of mammary SCC. The left inguinal lymph-node presented altered histological architecture due to invasion of the cortex and medullary by neoplastic epithelial cells, which were organized into nests, whose center was filled with keratin pearls. This report of mammary SCC in a female dog demonstrates the importance of an attentive oncological follow-up in cases of breast neoplasms with invasions in lymphatic vessels and relapses, even after surgical removal.
\end{abstract}

KEYWORDS: dog, squamous differentiation, breast neoplasm.

\section{INTRODUÇÃO}

Tumores mamários caninos (TMC) representam 50 a $70 \%$ de todos os tumores que acometem fêmeas caninas intactas (GOLDSCHMIDT et al., 2017), sendo reportada taxa de malignidade de aproximadamente 50\% (FOALE; DEMETRIUOU, 2011; SALAS et al., 2015).

As neoplasias da glândula mamária são classificadas quanto ao comportamento em benignas ou malignas. Histologicamente, a diferenciação entre tumores malignos e benignos se baseia no tipo, arranjo, invasão neoplásica, pleomorfismo e presença ou ausência de componentes mesenquimais não neoplásicos (SORENMO et al., 2013).

Propostas de classificação para os TMC têm sido descritas a fim de contribuir com a avaliação prognóstica, já que por vezes o subtipo histológico demonstra-se correlacionado a uma pior sobrevida (SOLANO-GALLEGO, 2012; RASOTTO et al., 2017).

Em estudo retrospectivo sobre neoplasias mamárias em cadelas, Andrade et al. (2017) verificaram que, dentre os carcinomas, o carcinoma simples (incluindo os sub-tipos "sólido" e "túbulo-papilar", "tubular" e "papilar") foi o mais frequente, seguido pelo carcinoma em tumor misto e carcinoma complexo. A neoplasia benigna mais frequente foi o adenoma simples, seguida do complexo.

Em cadelas, alguns tipos de neoplasias mamárias são menos frequentes, porém agressivas, como osteossarcoma mamário, carcinoma anaplásico, carcinoma rico em lipídeos, carcinoma micropapilar invasivo, carcinoma inflamatório, comedocarcinoma e carcinoma de células escamosas. Estas neoplasias apresentam um prognóstico desfavorável com menor tempo de sobrevida (JUBB et al., 2015). O 
CCE da mama em mulheres também é considerado uma neoplasia maligna rara, porém agressiva (YADAV et al., 2017).

Assim como o CCE cutâneo, o que ocorre na mama tem baixa capacidade de invadir vasos linfáticos e promover metástases em linfonodos, no entanto infiltração local é comum. Metástases podem ocorrer em estágios avançados da doença, quando os tumores já se desenvolveram por muito tempo, e o primeiro sítio acometido são os linfonodos regionais, em seguida pulmões e ossos (GOLDSCHMIDT et al., 2017; KRAEGEL; MADEWELL, 2004).

\section{RELATO DE CASO}

Uma cadela, sem raça definida, de dez anos de idade foi encaminhada para atendimento no Setor de Clínica Médica de Pequenos Animais do Hospital Veterinário da Universidade Federal de Uberlândia (HV-UFU), em maio de 2018. O tutor relatou que o animal apresentou tumor em mama dois meses antes da consulta, mas não soube informar qual era a glândula mamária acometida. $\mathrm{Na}$ ocasião a cadela foi submetida à nodulectomia em outra clínica veterinária e não foi realizada avaliação histopatológica, não foi definido o tipo histológico e houve recidiva.

Durante a anamnese especial foi relatado que o animal era castrado, apresentava perda de peso, respiração ofegante e possuía nódulos ulcerados, aderidos em musculatura, invadindo tecido adjacente, com secreção piohemorrágica, localizados em mamas abdominais caudais e mamas inguinais de ambos os lados. Ao exame físico observou-se mucosas normocoradas, linfonodos submandibulares reativos, respiração toraco-abdominal.

Foram solicitados como exames complementares: hemograma, dosagem de creatinina, ALT e albumina, ultrassonografia abdominal, $R X$ de tórax e exame citológico de esfregaço de material obtido por punção aspirativa por agulha fina (PAAF) dos nódulos descritos anteriormente.

No exame ultrassonográfico foi observado, na região inguinal esquerda, área com volume flutuante, localizada no subcutâneo, com conteúdo anecóico sugestivo de seroma. Havia ainda no líquido uma estrutura livre, de contorno definido, irregular, ecóica e homogênea, de aproximadamente $1,95 \mathrm{~cm}$, sugestivo de coágulo, e outra estrutura também livre, de contorno regular, definido, hiperecóica e homogênea, com cerca de 2,11 cm por $1,12 \mathrm{~cm}$, sugestivo de neoplasia mamária.

Os exames bioquímicos apresentaram-se dentro do padrão normal para a espécie e no hemograma foi verificada discreta policromasia e anisocitose. No exame radiográfico também não foram identificadas alterações. O exame citológico foi inconclusivo. O animal foi submetido à mastectomia total e o material encaminhado ao setor de Patologia Animal do HV-UFU, juntamente com linfonodos inguinais, para análise histopatológica.

\section{RESULTADOS E DISCUSSÃO}

O diagnóstico clínico foi de recidiva de carcinoma mamário. Na avaliação citológica o resultado foi inconclusivo, devido à hipocelularidade da amostra. Risati et al. (2016) relataram que existem limitações do exame citopatológico como forma diagnóstica nos casos de tumores de mama em cadelas.

Após exérese cirúrgica, foi enviado ao setor de Patologia Animal do HV-UFU cadeia mamária com cinco tetos, medindo $23,0 \mathrm{~cm}$ e bloco caudal (mamas abdominais caudais e inguinais de ambos os antímeros). Andrade et al. (2017) 
mostrou em seu estudo que a maioria das lesões mamárias acometem as mamas inguinais, seguidas pelas abdominais, assim como descrito neste caso.

Microscopicamente, observou-se em fragmentos das mamas abdominais caudais direita e esquerda e inguinais direita e esquerda células com formato que variava de arredondado a poliédrico, citoplasma amplo, eosinofílico, núcleo central, ovalado, cromatina frouxa e nucléolo evidente, por vezes múltiplos (Figura 1). As células se organizavam em ninhos, cujo centro encontrava-se preenchido por pérolas de queratina. Notou-se também pleomorfismo celular, com elevada anisocitose e anisocariose, uma figura de mitose por campo de grande aumento em média. As características morfológicas foram compatíveis com carcinoma de células escamosas, moderadamente diferenciado, em glândula mamária e os achados microscópicos foram semelhantes aos relatados por Goldschmidt et al. (2017).

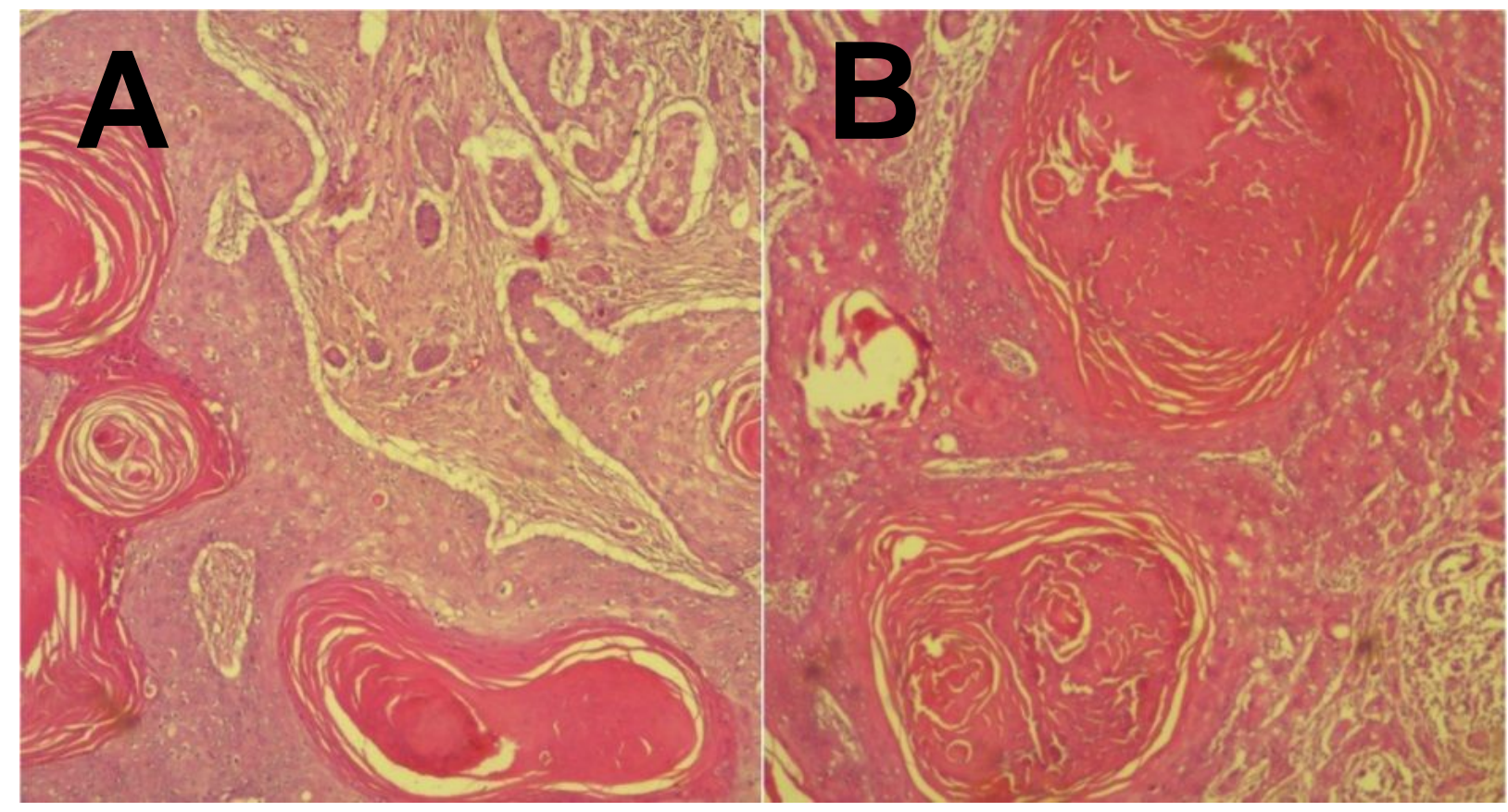

FIGURA 1 - Fotomicrografias de glândula mamária, cão, fêmea, 10 anos, objetiva 4X. Proliferação de células epiteliais arranjadas ora em ninhos, cujo centro se encontra preenchido por pérolas de queratina. Células com formato variando de arredondado a poliédrico, com citoplasma amplo, eosinofílico, núcleo central, ovalado, cromatina frouxa e nucléolo evidente, por vezes múltiplo.

O carcinoma de células escamosas mamário é composto exclusivamente de epitélio escamoso e esta característica deve ser utilizada para diferenciá-lo do carcinoma adenoescamoso mamário. A neoplasia tem sua origem nas células escamosas do ducto do teto ou de epitélio ductal, sendo que estas células sofreram metaplasia escamosa e transformação neoplásica (GOLDSCHMIDT et al., 2017).

O linfonodo inguinal enviado para avaliação histológica estava aumentado de volume e microscopicamente observou-se perda da arquitetura normal em decorrência da invasão do córtex e medular por células epiteliais neoplásicas, que se organizavam formando ninhos, cujo centro era preenchido por pérolas de 
queratina (Figura 2). Metástases de CCE em linfonodos regionais também foram verificadas por Silva et al. (2018) em seu estudo.

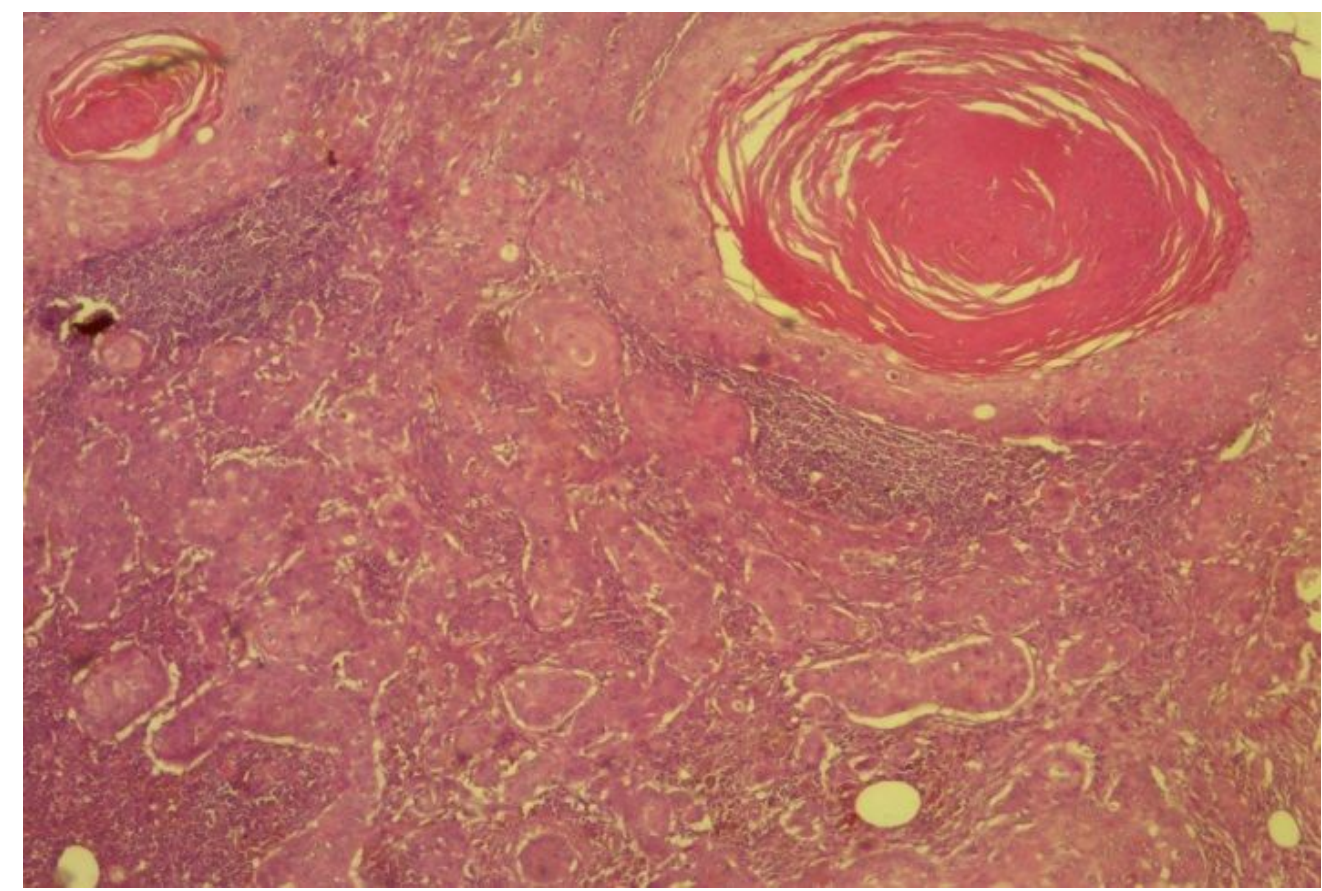

FIGURA 2 - Fotomicrografia de linfonodo inguinal, cão, fêmea, 10 anos, objetiva 4X. Perda da arquitetura normal em decorrência da invasão do córtex e medular por células epiteliais neoplásicas, que se organizavam formando ninhos, cujo centro era preenchido por pérolas de queratina.

Assim como acontece com a maioria dos carcinomas de células escamosas cutâneos, a invasão linfovascular e metástase linfonodal é incomum e ocorre apenas nos estágios tardios da doença quando os tumores são grandes e estão instalados a muito tempo (GOLDSCHMIDT et al., 2017). Os carcinomas de células escamosas cutâneos geralmente são bastante agressivos localmente, invadindo os tecidos subjacentes (ZACHARY et al., 2016) e, de acordo com Goldschmidt et al. (2002), se houver metástase o primeiro sítio acometido são os linfonodos regionais, o que foi possível observar neste estudo, que mostra invasão neoplásica em linfonodo regional.

\section{CONCLUSÃO}

Descreveu-se um caso de CCE mamário com metástase para linfonodo, que demonstra a importância de um acompanhamento oncológico atencioso em quadros de neoplasias mamárias com invasões em vasos linfáticos e recidivas, mesmo após remoção cirúrgica.

A avaliação histopatológica é essencial no caso de neoplasias mamárias, pois somente assim o tipo tumoral pode ser determinado e o adequado tratamento instituído. Por outro lado, a sensibilidade do exame citopatológico é bastante limitada na avaliação de neoplasias mamárias. 


\section{REFERÊNCIAS}

ANDRADE B. M; GUIMARÃES C. E; COLETO F. A; SOARES P. N; MEDEIROSRONCHI A. A. Estudo retrospectivo de lesões mamárias em cadelas - Uberlândia, MG, Brasil. Acta Scientiae Veterinariae. v. 45, p.1509, 2017. Disponível em: http://www.redalyc.org/articulo.oa?id=289053641003

FOALE, R.; DEMETRIOU, J. Oncologia em pequenos animais. Série clínica veterinária na prática. 1a ed. São Paulo: Elsevier, 2011.

GOLDSCHMIDT M. H.; HENDRICK M.J. Tumor of the skin and soft tissues. In: Meuten DJ, editor. Tumors in domestic animals. 4th ed. lowa: lowa State Press; $p$. 45-117, 2002.

GOLDSCHMIDT, M.H.; PEÑA, L.; ZAPPULLI, V. Tumors of the mammary gland. In: Meuten, D.J. Tumors in domestic animals. New Jersey: Wiley-Blackwell, 5ed, p.723-765, 2017..

JUBB; KENNEDY; PALMER'S. Pathology of domestic animals. 6 ed, v.3, p. 462. Canadá: Elsevier, 2015.

KRAEGEL, S. A.; MADEWELL, B. R. Tumores da Pele. In: ETTINGER, S. J.; FELDMANN, E. C. Tratado de Medicina Interna Veterinária. 5.ed. Rio de Janeiro: Guanabara/Koogan. cap. 99, p.555-557, 2004.

RASOTTO, R.; BERLATO, D.; GOLDSCHMIDT, M.H.; ZAPPULLI, V. Prognostic significance of canine mammary tumor histologic subtypes: an observational cohort study of 229 cases. Veterinary Pathology, v.54, n.4, p.571-578, 2017. Disponível em: http://journals.sagepub.com/doi/pdf/10.1177/0300985817698208 DOI: $10.1177 / 0300985817698208$

RISATI C.A ; DANEZE R. E; MAGALHÃES M.G. Comparação entre os diagnósticos citopatológico e histopatológico em neoplasias mamárias de cadelas. Science and Animal Health. v.4, n.1, p. 67-80, 2016. Disponível em: https://periodicos.ufpel.edu.br/ojs2/index.php/veterinaria/article/view/5225 DOI: http://dx.doi.org/10.15210/sah.v4i1.5225.

SALAS Y.; MÁRQUEZ A.; DIAZ D.; ROMERO L.; Epidemiological Study of Mammary Tumors in Female Dogs Diagnosed during the Period 2002-2012: A Growing Animal HEALTH PROBLEM. Plos One. v. 10, n. 5, 2015. Disponível em: https://www.ncbi.nlm.nih.gov/pubmed/25992997 DOI: 10.1371/journal.pone.0127381

SILVA C. I.; SARANDY B. T.; TAMIASSO V. V.; APTEKMANN P. K.; ANDRADE JUNIOR C. S. P.; BOELONI N. J. Metastatic submandibular acantholytic squamous cell carcinoma in a dog. Braz J Vet Pathol. v.11, n.1, p.19-23, 2018. Disponível em:https://www.researchgate.net/publication/324470920_Metastatic_submandibular acantholytic_squamous_cell_carcinoma_in_a_dog DOI: $10.24070 / \mathrm{bjvp} .1983-$ 0246.v11i1p19-23. 
SOLANO-GALLEGO, L. Sistema reprodutivo. In: RASKIN, R.E.; MEYER, D.J. Citologia clínica de cães e gatos - Atlas colorido e guia de interpretação. $2^{\mathrm{a}}$ ed. Rio de Janeiro: Elsevier, p.274-281, 2012.

SORENMO, K.U.; WORLEY, D.R; GOLDSCHMIDT, M.H. Tumors of the mammary gland. In: WITHROW, S.J.; MACEWEN'S, E.G. Small animal clinical oncology, 5aed.ElsevierSaunders: St. Louis, Missouri, p.538-556, 2013.

YADAV S.; YADAV D.; ZAKALIK D. Squamous cell carcinoma of the breast in the United States: incidence, demographics, tumor characteristics, and survival. Breast Cancer Res Treat. n. 2017, p. 164:201-208, 2017. Disponível em: https://search.proquest.com/openview/600db83d04cf7d9ab452fe50df7b8e41/1 ?pqorigsite=gscholar\&cbl=36266 DOI: 10.1007/s10549-017-4251-3.

ZACHARY F. J. Pathologic Basis of Veterinary Disease. 6 $6^{\underline{a}}$ ed. Saintt Louis: Elsevier Health Sciences, 2016. 